\title{
Indeterminate biliary stricture treated by antegrade cholangioscopy through an endoscopic ultrasound-guided hepaticojejunostomy
}

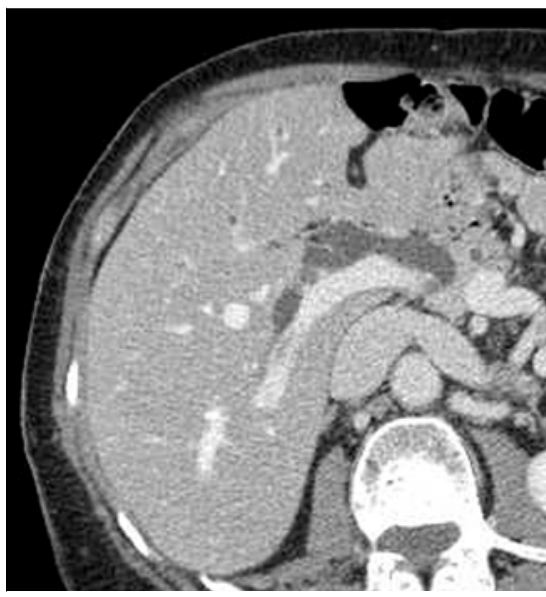

- Fig. 1 Abdominal computed tomography scan showing bile duct dilatation.

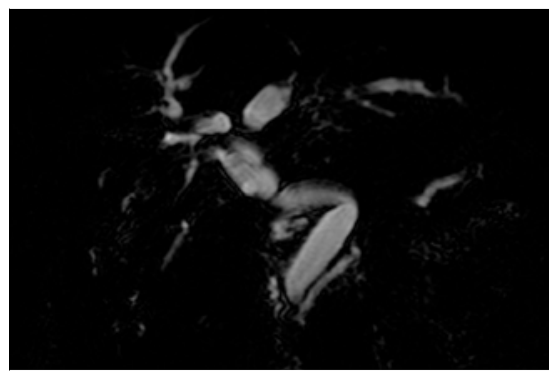

Fig. 2 Magnetic resonance cholangiopancreatography showing bile duct dilatation and a filling defect in the papillary area.

Indeterminate biliary strictures represent a clinical challenge [1,2]. Endoscopic retrograde cholangiopancreatography (ERCP) with brushings and transpapillary biopsies have limitations in terms of their sensitivity and specificity $[3,4]$. Cholangioscopy plays a relevant role in this field with a high sensitivity for the macroscopic appearance [5].

A 60-year-old woman, who had undergone total gastrectomy with Roux-en-Y reconstruction for gastric adenocarcinoma (pT2 N0 M0) 4 years previously, presented to our ambulatory unit with upper abdominal pain and alteration of liver
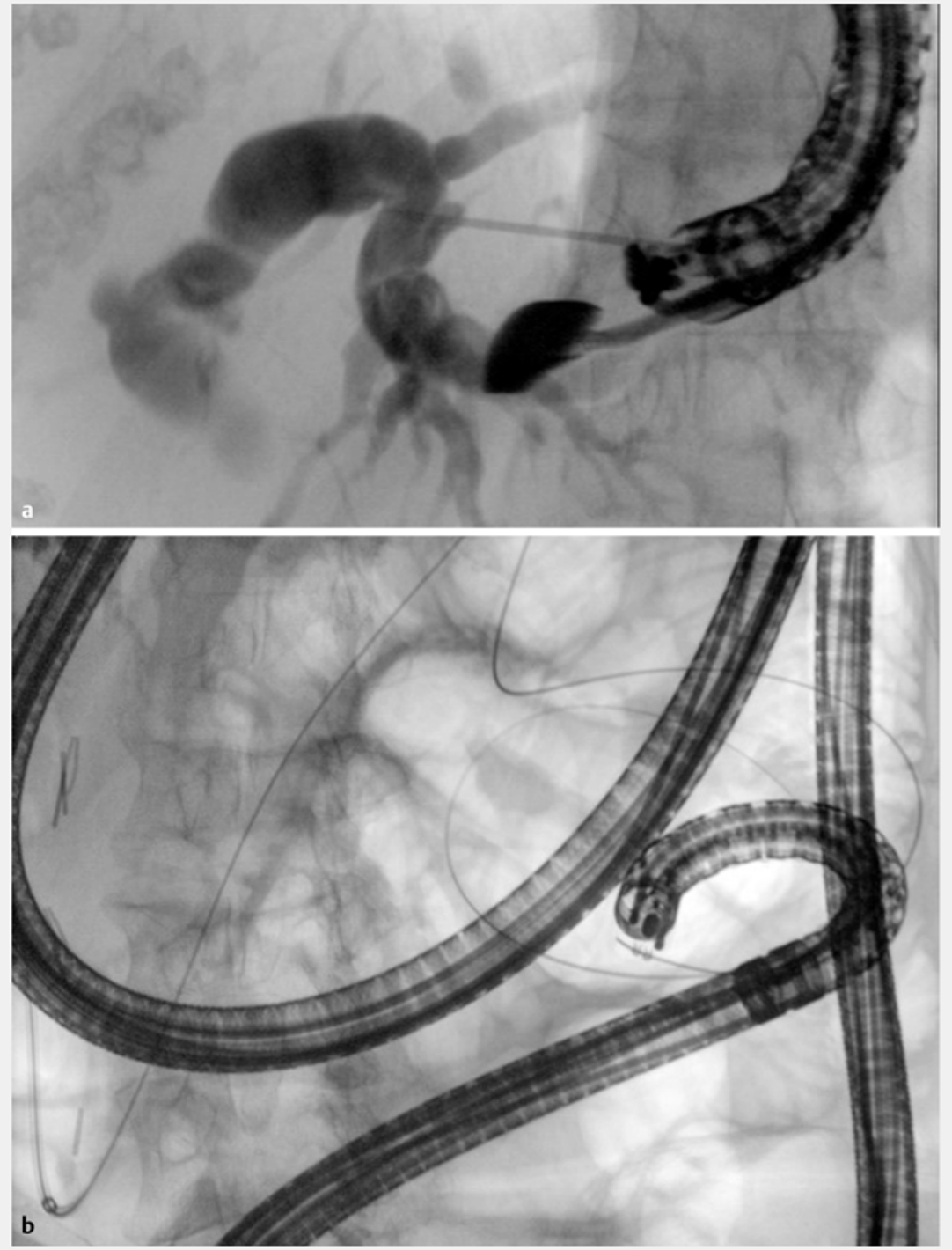

- Fig. 3 Fluoroscopic images showing: a an endoscopic ultrasound-guided hepaticojejunostomy being created; $\mathbf{b}$ the guidewire that had been passed through the transjejunal access and through the papillary area retrogradely being recovered with the pediatric colonoscope.

function tests. An abdominal computed tomography scan ( $>$ Fig. 1 ) and magnetic resonance cholangiopancreatography $(\mathrm{MRCP})(>$ Fig. 2$)$ showed bile duct dilatation and a distal stricture of the common bile duct. However, an endoscopic ultrasound (EUS) approach was not feasible or effective because of her altered anatomy.

A first attempt to reach the papillary area and perform a subsequent ERCP using a pediatric colonoscope was unsuccessful owing to the length and angulations of the jejunal loop. Therefore, a hepatico- 


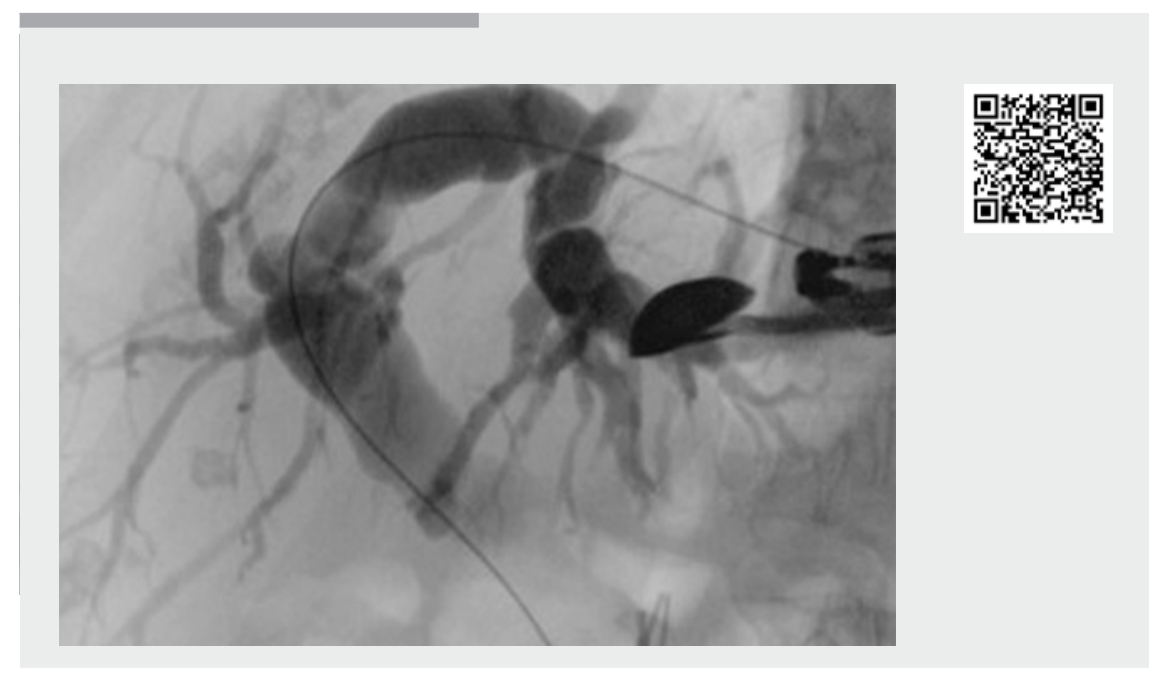

$\checkmark$ Video 1 Antegrade cholangioscopy through an endoscopic ultrasound-guided hepaticojejunostomy to treat a biliary indeterminate stricture in a patient with Roux-en-Y reconstruction.

jejunostomy was performed endoscopically ( $\triangleright$ Fig. 3 a). First, a transjejunal hepatic EUS-guided puncture was done using a $19 \mathrm{G}$ needle. A guidewire was pushed through the transjejunal access through the papillary area retrogradely and was recovered through the pediatric colonoscope ( $\mathbf{F i g . 3} \mathbf{b}$ ). The papilla was cannulated from distance under fluoroscopic guidance (because of a tight angulation at Treitz's ligament) using a 12-mm Fogarty balloon. Cholangiography confirmed homogeneous dilatation of the bile ducts with a distal stricture. The stricture was dilated using a $10-\mathrm{mm}$ pneumatic balloon; brushings and transpapillary biopsies were then performed. A 10-Fr 12-cm biliary plastic stent was left in place to maintain patency of the endoscopic hepaticojejunostomy.

Because the cytology was non-diagnostic, antegrade cholangioscopy using the SpyGlassDS system (Boston Scientific Co.) was successfully performed through the endoscopic hepaticojejunostomy 2 weeks later ( $\triangleright$ Video $\mathbf{1}$ ). The appearance of the stricture was non-malignant; several cholangioscopic biopsies were taken using a SpyBite (Boston Scientific Co.), which later confirmed there was no cellular atypia on histopathology. Finally, a $10-\mathrm{Fr} 12-\mathrm{cm}$ biliary plastic stent was positioned through the hepaticojejunostomy.

No early adverse events occurred and the patient was discharged the day after the procedure. At her 1-month follow-up visit, the patient had developed two liver abscesses (S4-S8), which were probably related to bile duct contamination during the cholangioscopy. Percutaneous drainage of the abscesses was performed, and the patient was found to be doing well at her 3-month follow-up visit.

Endoscopy_UCTN_Code_TTT_1AS_2AD

\section{Competing interests}

The authors declare that they have no conflict of interest.

The authors

\section{Roberto Rosa, Lorenzo Dioscoridi, Edoardo} Forti, Francesco Pugliese, Marcello Cintolo, Giulia Bonato, Massimiliano Mutignani Digestive Endoscopy Unit, ASST Niguarda, Milan, Italy

\section{Corresponding author}

\footnotetext{
Massimiliano Mutignani, MD

Piazza dell'Ospedale Maggiore 3, 20158 ,

Milan, Italy

Fax: +39-02-64448565

massimiliano.mutignani@ospedaleniguarda. it
}

\section{References}

[1] Singh A, Gelrud A, Agarwal B. Biliary strictures: Diagnostic considerations and approach. Gastroenterol Rep (Oxf) 2015; 3: 22-31

[2] Kato M, Onoyama T, Takeda Y et al. Peroral cholangioscopy-guided forceps biopsy and endoscopic scraper for the diagnosis of indeterminate extrahepatic biliary stricture. J Clin Med 2019; 8: 1-11

[3] Ponchon T, Gagnon P, Berger F et al. Value of endobiliary brush cytology and biopsies for the diagnosis of malignant bile duct stenosis: results of a prospective study. Gastrointest Endosc 1995; 42: 565-572

[4] Burnett AS, Calvert TJ, Chokshi RJ. Sensitivity of endoscopic retrograde cholangiopancreatography standard cytology: 10-y review of the literature. J Surg Res 2013; 184 : 304-311

[5] Navaneethan U, Njei B, Lourdusamy V et al. Comparative effectiveness of biliary brush cytology and intraductal biopsy for detection of malignant biliary strictures: A systematic review and meta-analysis. Gastrointest Endosc 2015; 81: 168-176

\section{Bibliography}

Endoscopy 2020; 52: 1143-1144

DOI 10.1055/a-1149-8684

ISSN 0013-726X

published online 24.4 .2020

(c) 2020. Thieme. All rights reserved. Georg Thieme Verlag KG, Rüdigerstraße 14, 70469 Stuttgart, Germany

\section{ENDOSCOPY E-VIDEOS \\ https://eref.thieme.de/e-videos}

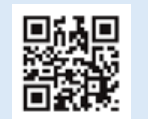

Endoscopy E-Videos is a free access online section, reporting on interesting cases and new techniques in gastroenterological endoscopy. All papers include a high quality video and all contributions are freely accessible online.

This section has its own submission website at https://mc.manuscriptcentral.com/e-videos 